\title{
PERCEPTION OF TERROR RISK AND OF THE SECURITY OF COUNTER- TERRORISM DESIGN IN PUBLIC SPACES
}

\author{
Husnul Fitri Sundoko ${ }^{1,2^{*}}$, Roos Akbar $^{2}$, Denny Zulkaidi ${ }^{2}$, Teti Armiati Argo ${ }^{2}$ \\ ${ }^{1}$ Indonesia Institute for Defence and Strategic Studies-LESPERSI, Jl. Petogogan I/30 Blok A Kebayoran \\ Baru Jakarta Selatan, 12620, Indonesia \\ ${ }^{2}$ School of Architecture, Planning and Policy Development, Institut Teknologi Bandung, Gedung Labtek \\ IXA Lantai II Jl. Ganesha No. 10 Bandung, West Java 40132, Indonesia
}

(Received: April 2016 / Revised: October 2017 / Accepted: March 2018)

\begin{abstract}
At a time of terror, research on the perception of terror risk makes an important contribution to increase understanding of the public perception of terror threat. This kind of research can be utilized to improve strategies for raising the sense of security in public spaces. Since 9/11, efforts to promote this sense of security have been implemented through the development of security features embedded in public spaces, known as counter-terrorism design. It is assumed that terror risk perception can affect the perception of security in this design strategy. To investigate this issue, research was conducted on three business districts which represented high-profile terror attack targets in Jakarta. The primary findings of the study confirm the research assumption, but the role of terror risk perception was less strong than expected as the main predictor to determine the perceived security of counter-terrorism design. In addition, the study also found that gender had a significant but low influence on the security perception of counter-terrorism design.
\end{abstract}

Keywords: Counter-terrorism design; Risk perception; Security

\section{INTRODUCTION}

Historically, the city has always been a place of conflict, dispute, war, crime and terror (Bugliarello, 2003; Beall, 2006; Coaffee et al., 2009; Sassen, 2010). Graham (2004) uses the term "urbicide" to describe the condition of the city, which has always been the target of series of violent action. The selection of urban areas as arenas of conflict and violence is inseparable from the particular attributes inherent in a city. The characteristics of high density, complex infrastructure, concentration of high-value assets and also the international profile of cities as centers of politics, conflict, mass media, intellectual life and multiethnic communities have made them the central focus for social threats and violence (Savitch, 2008). This condition has translated the face of the urban community into a risk society.

Currently, cities have to confront the evolution of the pervasive risk that intimidates urban life, i.e. terrorism. Terrorism has been perceived as a severe and extreme form of threat, with an increasing tendency in various cities around the world, including Indonesia. It was $9 / 11$ that served as a wake-up call for terrorism, and which was followed by a war on terror campaign that escalated this threat.

\footnotetext{
*Corresponding author's email: rum1328@yahoo.com, Tel. +62-21-7252725, Fax. +62-21-7262305 Permalink/DOI: https://dx.doi.org/10.14716/ijtech.v9i3.1931
} 
In line with this situation, there have been various efforts to find effective approaches to protect people from terror attacks in urban areas. In the field of planning and urban design, these attempts are represented, among other approaches, by the use of strategy and security features integrated into the planning and designing public spaces, which is referred to as counter-terrorism design. This involves the implementation of security features in designing and managing public spaces, particularly in high profile areas which may be prime targets for terror attack. In this context, spaces and built environments are planned through a defensive-design approach, supplemented by certain security strategies to provide a sense of security in the face of the terror threat.

Counter-terrorism design is defined as a defensive design arrangement involving physical space and security features for preventing, responding to and mitigating terror attacks which comprises elements of spatial or physical settings, technology and people (Grosskopf, 2006; Schneider \& Kitchen, 2007). Preventive aspects are focused on efforts to prevent the occurrence of terror attacks in specific areas by performing zoning and target hardening. At the same time, responsive approaches deal with the endeavor to rebuild previous areas of terror targets, such as the revitalization of Ground Zero in New York. On the other hand, the mitigation dimensions are directed towards reducing vulnerability and any further impact caused by terror incidents. For this study, counter-terrorism design is focused on the preventive aspect, as it involves modification and implementation of security features within built environment.

Regarding the term 'counter-terrorism', it is often used interchangeably with 'anti-terrorism'. Both are used differently in different countries. In the United States, for example, it is more common to use 'anti-terrorism' to distinguish it from counter-terrorism. Counter-terrorism is often related to offensive strategy, while anti-terrorism is associated with the defensive aspect. On the contrary, the United Kingdom and Indonesia often use the term counter-terrorism to describe all the efforts, from offensive to defensive strategies, for combating terror. For this study, the term counter-terrorism will be used, as it is generally applied in Indonesia.

Counter-terrorism design is commonly assigned to high profile locations considered as potential targets of terror attacks. Several countries with high terror risks, such as the United States and the United Kingdom, are among the forerunners in applying this approach. It can be noticed in the use of numerous barriers and gates and panoptic equipment in public spaces. Temporary or permanent barriers have become a common sight in locations where terror attacks have taken place, and also in public spaces assumed to have a high risk of being attacked by terrorists.

These special designs also take many forms, from hard and visible, to soft and invisible features. The former, usually called obtrusive counter-terrorism design, represents the purpose of the security function literally, in many forms of design that can be easily recognized, such as jersey and guard barriers. The latter, an unobtrusive counter-terrorism design which has the opposite characteristics to obtrusive design, emphasizes not only the security function, but also the aesthetic features to make it blend and become embedded into the existing environmental design. Bollards, decorative fences and planters, including attractive modifications to them, are among many examples of this type of unobtrusive design. Practically, both these counter-terrorism designs can be seen in several high-profile locations in New York, London and Belfast. Similar sights also can be found in Jakarta, particularly in some embassies, malls, streets and business districts.

The main purposes of applying counter-terrorism design are not only to prevent the occurrence of terror action in potential target locations, but also to physically protect the people in those locations from terror incidents. The success of the latter objective can be observed by analyzing public perception of the sense of security. If this sense increases with the presence of counterterrorism design, then it probably indicates that the existing security design has managed to achieve the goals expected. However, there are several factors that influence the perception of 
public security. One influential and important factor is risk perception.

Risk perception can be defined as the identification of people's emotional reactions to risky situations which affect judgments beyond their objective consequences (Slovic \& Weber, 2002). According to Sheppard (2011), risk perception serves as a central element in analyzing the societal response to a specific risk and the action taken. Research on the risk perception of terrorism is usually focused on the efforts to find a relationship between attributes affecting the perception of terror risk, such as socio-demographic factors (Fischhoff et al., 2003; Sjöberg, 2005; Lemyre et al., 2006; Lee \& Lemyre, 2009; Bozzoli \& Muller, 2011) or the proximity to potential terror targets (Fischoff et al., 2003; Woods et al., 2008). Meanwhile, other studies have attempted to reveal the relationship between risk perception and behavioral coping strategy (Lee \& Lemyre, 2009) or preparedness behavior (Stevens et al, 2009; Borque et al., 2013). However, studies that focus on the relationship between the perception of terror risk and the sense of security in relation to the physical security features in public spaces are rare. In comparison, there has been much research conducted in the criminology field which analyzes the perception of risk and its relationship to specific security design, despite the use of different terminology such as fear of crime (Jackson, 2006), fear of victimization (Ferraro, 1996), perceived safety (Loewen et al., 1993) or perceived danger (Blobaum \& Hunecke, 2005; Herzog \& Miller, 1998). The general conclusions from these studies provide evidences that there is a strong relationship between perception and physical design in the built environment (Fisher \& Nasar, 1992; Loewen et al., 1993; Nasar \& Fisher, 1993; Nasar \& Jones, 1997; Blobaum \& Hunecke, 2005; Andrews \& Gatersleben, 2010).

Studies analyzing the relationship between perception of terror risk and sense of security in relation to counter-terrorism design have become important because they provide information on determining whether this risk perception affects public judgment in evaluating physical security features in public spaces that contribute to people's feelings of safety. If this perception influences the public sense of security, then the efforts to provide the best security design in public spaces will not have any effect, since such perception dominates individuals' assessment of the security and safety of the environment. Therefore, it is necessary to conduct a study on this issue so that manipulation of physical design as a part of counter-terrorism strategy can have the maximum impact on people's sense of security. In addition, this study also involves the analysis of demographic factors, including sex, age and education. Previous studies have verified that specific demographic attributes make a difference to perception in the context of terrorism (Fischhoff et al., 2003; Woods et al., 2008; Lee \& Lemyre, 2009). Specifically, in various studies women have consistently tended to have a higher risk perception than men (Fischhoff et al., 2003; Lemyre et al., 2006; Bozzoli \& Muller, 2011). Meanwhile, different results have been found for other attributes, such as education and age. Lemyre et al. (2006) found that those who were highly educated and older had a higher risk perception. On the contrary, another study conducted by Bozzoli and Muller (2011) showed that a higher perception was found in groups with lower education levels.

Regarding the age factor, it is believed that older people have higher and better feelings of control, which affect the ability to make judgments on threats and dangers (Fischhoff et al., 2003). Fischhoff et al. specifically found that in the middle age groups, feelings of fear will be reduced according to the distance from the locations of terror attacks. Meanwhile, another study in the context of crime concluded that younger age groups have higher levels of fear (Bachman et al., 2011). Thus, the information about the influence of the age attribute needs to be elaborated in this study. 


\section{METHODOLOGY}

\subsection{Research Design}

Since the study focuses on the efforts to capture aggregate knowledge of public perception, a quantitative approach was primarily used for this purpose. In this way, the study of perception could be perceived as empirical experiences involving human mental processes to identify the physical aspects of the stimulus. Therefore, the measurement of inner and intangible processes could be translated into scientific quantification.

\subsection{Participants}

A total of 295 participants were the sample for the study (167 males and 128 females). They were derived from professional employees working daily in the buildings surrounding the location of past target attacks, with a maximum radius of $5 \mathrm{~km}$. Three sites served as the central point of this radius: the Australian Embassy (attack in 2009), the JW Marriot/Ritz-Carlton hotel (attacks in 2003 and 2009) and the Jakarta Stock Exchange/BEJ (attack in 2000). Both the Australian Embassy and the JW Marriot/Ritz-Carlton hotel are located in the Kuningan business district, while the BEJ is sited in the Sudirman business district. Demographic information for the sample included age, sex and education (Table 1).

The respondents' ages were divided into groups according to their developmental stage. This classification was made to show the influence of specific age phases on perception. As shown in Table 1, there were three developmental stage age attribute groups: teenagers/youths (18 years old), young adults (19-35 years old), and middle-aged adults (36-60 years old). The further stage of development (old age or late adulthood) was represented in the sample.

With regard to educational characteristics, the sample represented six levels of the respondents, ranging from elementary to postgraduate degree. Respondents with an undergraduate background (Strata 1) dominated the sample, followed by high school graduates.

Table 1 Demographic characteristics of respondents

\begin{tabular}{lrr}
\hline \multicolumn{1}{c}{ Demographic Attributes } & \multicolumn{1}{c}{$\%$} \\
\hline Sex & & \\
$\quad$ Male & 167 & 56.6 \\
$\quad$ Female & 128 & 43.4 \\
Age & & \\
18 & 8 & 2.7 \\
$19-35$ & 203 & 68.8 \\
36-60 & 84 & 28.5 \\
Education & & \\
$\quad$ Elementary & 6 & 2.0 \\
$\quad$ Junior high school & 17 & 5.8 \\
$\quad$ High school & 111 & 37.6 \\
College/Diploma & 13 & 4.4 \\
$\quad$ Undergraduate & 124 & 42.0 \\
$\quad$ Postgraduate & 24 & 8.1 \\
Total & 295 & 100 \\
\hline
\end{tabular}

\subsection{Instruments}

Data collection was made through the survey method. The paper-based questionnaire used in the study consisted of two scales. The first scale contained three risk perception items. In this scale, the respondents were asked to evaluate their feeling, cognition and behavior towards terror attacks; for example, "To what extent do you currently worry about the probability of terrorist attack?" The reliability of $\alpha$ Cronbach for this scale was 0.84 . The second scale assessed feelings 
of security in relation to counter-terrorism design in public spaces and was composed of 24 items. Basically, samples of counter-terrorism design in this scale represented four design strategies, namely design modification to monitor potential criminals (surveillance); design for controlling and regulating access to potential targets (access); management of design functions to control the presence of strangers (animation; and design that limits the concealment of certain dangerous objects (concealment). The respondents were asked about their sense of security regarding these kinds of strategy, such as "CCTV cameras in public spaces are effective in deterring terrorist attacks"; "To prevent terrorist attacks, access to public space needs to be restricted"; "Public space must have limited/specific/particular functions to organize crowds and to increase security against terrorist threat." The $\alpha$ Cronbach was 0.81 . These two measurements applied 5-point Likert-type scales ranging from "very worried" to "not worried at all" (for the risk perception scale) and "not agree at all" to "totally agree" (for the counter-terrorism design scale). For statistical analysis, the scores were converted into interval scales using the successive interval (MSI) method.

\subsection{Procedure}

The questionnaire was administered by delivering it to the offices of the respondents. Unfortunately, because the topic of the research was perceived to be quite sensitive from the perspective of the formal security of the selected offices, some offices refused to give permission for the distribution of the questionnaire.

\section{RESULTS}

The overall perception of the respondents was quite high, as reflected in the mean score of terror risk perception $(\mathrm{M}=9.30 ; \mathrm{SD}=2.51)$ and security perception of counter-terrorism design $(\mathrm{M}=$ 15.09; $\mathrm{SD}=1.90$ ). A regression model was applied to analyze the relationship between terror risk perception and the perceived security of counter-terrorism design. It was revealed that there was a significant relationship between these two variables, but that the nexus was less strong (Beta = $.29 ; \mathrm{p}=.000)$. Meanwhile, the influence of terror risk perception as a predictor was only $8 \%(\mathrm{R} 2$ $=0.08)$.

In addition to these results, the elaboration of the perception of specific counter-terrorism design strategies could provide richer information to understand the preferences amongst such measures for security purposes. The Friedman test results showed a significant difference between the various strategies of counter-terrorism design, $\mathrm{c} 2(3, \mathrm{~N}=295)=57.87, \mathrm{p}=0.00$. These results indicated that the surveillance strategy was perceived as making the greatest contribution to the perception of security, based on the calculation of the mean rank (Table 2). If sorted in hierarchical sequence, the strategies of access and concealment were placed the second and third ranks, while animated was perceived as the least effective strategy contributing to security perception.

Tabel 2 Mean rank of respondents' security perception of counter-terrorism strategies

\begin{tabular}{lc}
\hline \multicolumn{1}{c}{ Strategy } & Mean Rank \\
\hline Animated & 2.12 \\
Concealment & 2.40 \\
Access & 2.63 \\
Surveillance & 2.85 \\
\hline
\end{tabular}

This analysis was also confirmed in the comparison with the mean scores of the existing design strategies presented in Figure 1. Surveillance posited the highest mean $(M=20.58, S D=3.48)$, 
followed respectively by access $(\mathrm{M}=19.77, \mathrm{SD}=3.92)$, concealment $(\mathrm{M}=19.34, \mathrm{SD}=3.40)$ and animated $(\mathrm{M}=18.56, \mathrm{SD}=3.60)$.

On the other hand, the low relationship between terror risk perception and perceived security of counter-terrorism design indicated that there were other factors that played a significant role in determining the security perception of counter-terrorism design. Therefore, analysis of demographic factors (sex, age and education) was made to find the influence of these factors.

Table 3 Perceived security of counter-terrorism design by demographic factors

\begin{tabular}{lcc}
\hline \multicolumn{1}{c}{ Factors } & Mean & SD \\
\hline Sex & & \\
$\quad$ Male & 14.98 & 1.80 \\
$\quad$ Female & 15.24 & 2.02 \\
Age & & \\
18 & 15.98 & 1.61 \\
$19-35$ & 14.91 & 1.67 \\
36-60 & 15.46 & 2.34 \\
Education & & \\
$\quad$ Elementary & 14.62 & 1.24 \\
$\quad$ Junior high school & 14.87 & 1.76 \\
$\quad$ High school & 15.27 & 2.00 \\
$\quad$ College/Diploma & 15.41 & 1.68 \\
$\quad$ Undergraduate & 15.12 & 1.79 \\
$\quad$ Postgraduate & 14.24 & 2.20 \\
\hline
\end{tabular}

The mean scores of the perceived security of counter-terrorism design were elaborated by noting the demographic characteristics of the respondents (Table 3). As shown in Table 3, female respondents had higher mean scores. The same result also applied to younger respondents (the group of 18-year-olds) and college/diploma graduates. Meanwhile, to determine the influence of demographic factors on the security perception of counter-terrorism design, assessment of an analysis of variance (ANOVA) test was performed.

Table 4 displays the ANOVA results for the impact of demographic factors on the perceived security of counter-terrorism design. Sex was clearly the only factor that had a significant influence. But similar to terror risk perception, the effect of this factor was weak. The score of Partial Eta Squared was only 0.02, which was lower than the influence of perception of terror risk.

Table 4 ANOVA results: influence of demographic factors on perceived security of counterterrorism design

\begin{tabular}{lcccccc}
\hline Factors & Type III Sum of Squares & df & Mean Square & F & Sig & Partial Eta Squared \\
\hline Sex & 16.13 & 1 & 16.13 & 4.73 & .03 & .02 \\
Age & 7.37 & 1 & 7.37 & 2.16 & .14 & .00 \\
Education & 1.32 & 1 & 1.32 & .388 & .53 & .00 \\
\hline
\end{tabular}

Notes. Sex was scored 1 = male and 2 = female; age was 1 = 18 y.o., 2 = 19-35, 3 = 36-60; education was 1 = elementary, $2=$ junior high school, $3=$ high school, $4=$ college/diploma, $5=$ undergraduate, $6=$ postgraduate

The results of this analysis showed that perception of terror risk and demographic factors were not dominant attributes contributing to the perceived security of counter-terrorism design. 


\section{DISCUSSION}

Based on the results of the quantitative analysis, the perception of terror risk had a weak impact on the perceived security of counter-terrorism design. The presence of this weak influence might be explained by the concept of personal control. A terror incident is an event that is both extreme and unpredictable, so individuals have difficulty making a rational risk evaluation. These conditions reduce the judgment of personal control and cause a sense of powerlessness (Migliorini et al., 2008). This attitude then motivates respondents to contend that the various forms of security design will remain relatively ineffective in overcoming terror actions. Therefore, this will lead to less impact to the effect of individual protection and security.

On the other hand, this research sampled respondents residing in the inner zone, closest to the location of the terror targets that are regarded as the critical zone. Respondents in this zone were also probably mostly exposed to the modifications and improvements in security features in public spaces to anticipate terror attack. However, these were still not enough to prevent terror occurrence in this high-profile location. This probably made respondents skeptical about the various security features in the public spaces. The same situation was also found in the study conducted by Koskela and Pain (2000) in the context of traditional crime. Therefore, although the respondents' perception of terror risk was quite high, it did not directly affect their judgment and evaluation of the sense of security provided by the security design.

In addition, the low relationship between risk perception and perceived security of counterterrorism design also showed respondents' lack of sensitivity to the implementation of physical design to protect people from terror attack. The design may be deemed to be a passive approach in providing protection and security (Brower et al., 1983). These conditions cause physical representation of the security features to be considered as less important than any active approach towards terror threats, such as military and formal organizational approaches. This is understandable, because the approach of urban design and planning practice for securing public space has never been formally introduced as part of counter-terrorism strategy in Indonesia. This circumstance, although perceived as a drawback in our policy, can also be seen as an opportunity to begin implementing counter-terrorism design based on the best practice learnt from other countries. This includes anticipating any weakness in or criticism of this approach.

On the other hand, the results from this research also need to be evaluated by considering the circumstances of the study. It was conducted in normal conditions, without the occurrence of any terror attacks. Thus, the feeling of fear and worry about terror would not be as intense as in a post attack state, because of the influence of the recency effect (Bozzoli \& Mueller, 2011; Rittichainuwat, 2011).

Although security features were perceived to have little capability of bringing a sense of security to the physical security measures, the study finally revealed preferences for certain types of counter-terrorism design. Statistical analysis showed that surveillance was perceived by respondents as the primary strategy which could contribute to the feeling of security and provide preferred protection in public spaces. Studies conducted by Grosskopf (2006) and Milman et al. (1999) also found that the existence of surveillance was the preferred strategy for providing a sense of security from the terror threat. Nevertheless, Grosskopf (2006) explains that surveillance was preferred due to its passive nature, rather than obtrusive physical intervention that could affect public daily activity.

Currently, the implementation of surveillance strategies in public spaces is mostly dominated by technological surveillance, rather than physical-based surveillance. Before surveillance technology become well-known as it is today, the idea of surveillance was first introduced through the manipulation of physical design. It became prominent in theoretical and also practical areas of the field of urban planning and design, particularly in the area of crime prevention 
through environmental design. This legacy can be learnt from the principles of 'eyes on the street' (Jacobs, 1961) or 'defensible spaces' (Newman, 1972). Both of these theories stress the involvement of society in observing strangers in certain manipulated physical designs. But current development of technological surveillance can replace not only physical-based surveillance, but also social participation in spaces, because of the increasing dependency on surveillance technology (Koskela, 2000, 2003). Criticism of this situation has been widely made and the issue debated in the planning field. Unfortunately, this study has not specifically revealed preferences for certain types of surveillance strategy.

In line with the results, demographic factors were also shown to have a minor influence on the perceived security of counter-terrorism design; the study found that gender had a significantly high impact. This confirms a number of previous studies, which have shown that there are significant differences in the perception of security in relation to certain security design which are caused by gender differences. In this case, women tend to have higher security perception than men. Thus, the existence of security features in public spaces to prevent terrorism could successfully provide a sense of security for the group of females, but not the males. Meanwhile, other demographic factors in this study, such as age and education, denoted no significant influence on the security perception of counter-terrorism design.

\section{CONCLUSION}

Few studies involving terror risk and physical security features are to be found in Indonesia. As a pioneering study in this field, this research serves as a preliminary study to increase understanding of terror risk perception in the case of counter-terror efforts, specifically in the field of urban planning and design.

A key finding of the study demonstrates that risk perception makes no major contribution to the perceived security of counter-terrorism design. Therefore, people's sense of security in relation to physical features is not directly influenced by their subjective risk evaluation. This opens the possibility of implementing physical security features appropriately, as an approach to protecting people in the case of terror attack, which will lead to a public sense of security. In particular, it also can be concluded from the study that there is tendency to depend on the use of surveillance to inhibit terror attack in public spaces. However, this result needs to be explored more fully in the future to determine whether technological or physical-based surveillance serve better to increase the perception of security and to protect people from terror attack.

At this point, the best practical implementation to enhance the perception of security and to secure public spaces can be made by combining physical and organizational approaches. When surveillance strategy outpaces other counter-terrorism features, the presence of human control and technological devices as a popular strategy for surveillance in public spaces, which slowly diminishes the surveillance-based physical strategy, needs to be maintained appropriately to prevent uncomfortable situations such as discrimination and intervention of privacy. On the other hand, public understanding of the role of planning and design should also be increased to establish public knowledge about the capability of physical design to provide secured public spaces in this age of terror. The study also points out that demographic factors have no great impact on the security perception of counter-terrorism design. This finding also needs to be examined further by involving more socio-demographic attributes, such as personal income and subjective experience. 


\section{REFERENCES}

Andrews, M., Gatersleben, B., 2010. Variations in Perceptions of Danger, Fear and Preference in a Simulated Natural Environment. Journal of Environmental Psychology, Volume 30, pp. 473-481

Bachman, R., Randolph, A., Brown, B.L., 2011. Predicting Perceptions of Fear at School and Going to and from School for African American and White Students: The Effects of School Security Measures. Youth \& Society, Volume 43(2), pp. 705-726

Beall, J., 2006. Cities, Terrorism and Development. Journal of International Development, Volume 18(1), pp. 105-120

Blobaum, A., Hunecke, M., 2005. Perceived Danger in Urban Public Space: The Impacts of Physical Features and Personal Factors. Environment and Behavior, Volume 37(4), pp. 465486

Borque, L.B., Regan, R., Kelley, M.M., Wood, M.M., Kano, M., Mileti, D.S., 2013. An Examination of the Effect of Perceived Risk on Preparedness Behavior. Environment and Behavior, Volume 45(5), pp. 615-649

Bozzoli, C., Muller, C., 2011. Perceptions and Attitudes to a Terrorist Shock: Evidence from the UK. European Journal of Political Economy, Volume 27, pp. S89-S106

Brower, S., Dockett, K., Taylor, R.B., 1983. Residents' Perceptions of Territorial Features and Perceived Local Threat. Environment and Behavior, Volume 15(4), pp. 419-437

Bugliarello, G., 2003. Urban Security in Perspective. Technology in Society, Volume 25, pp. 499507

Coaffee, J., Wood, D.M., Rogers, P., 2009. The Everyday Resilience of the City: How Cities Respond to Terrorism and Disaster, Palgrave Macmillan, Hampshire

Federal Emergency Management Agency (FEMA), 2007. Risk Management Series: Site and Urban Design for Security. FEMA Publication

Ferraro, K.F., 1996. Women's Fear of Victimization; Shadow of Sexual Assault? Social Forces, Volume 75(2), pp. 667-690

Fischhoff, B., Gonzales, R.M., Small, D.A., Lerner, J.S., 2003. Judged Terror Risk and Proximity to the World Trade Center. The Journal of Risk and Uncertainty, Volume 6 (2/3), pp. 137151

Fisher, B.S., Nasar, J.L., 1992. Fear of Crime in Relation to Three Site Features: Prospect, Refuge and Escape. Environment and Behavior, Volume 24(1), pp. 35-65

Graham, S., 2004. Cities, War and Terrorism: Towards an Urban Geopolitics. Blackwell, Oxford

Grosskopf, K.R., 2006. Evaluating the Societal Response to Antiterrorism Measures. Journal of Homeland Security and Emergency, Volume 3(2), pp. 1-9

Herzog, T.R., Miller, E.J., 1998. The Role of Mystery in Perceived Danger and Environmental Preference. Environment and Behavior, Volume 30(4), pp. 429-449

Jackson, J., 2006. Introducing Fear of Crime to Risk Research. Risk Analysis, Volume 26(1), pp. 253-264

Jacobs, J., 1961. The Death and Life of Great American Cities, New York, Random House

Koskela, H., 2000. 'The Gaze Without Eyes': Video-Surveillance and the Changing Nature of Urban Space. Progress in Human Geography, Volume 24(2), pp. 243-265

Koskela, H., 2003. 'Cam Era' - the Contemporary Urban Panopticon. Surveillance \& Society, Volume 1(3), pp. 292-313

Koskela, H., Pain, R., 2000. Revisiting Fear and Place: Women's Fear of Attack and the Built Environment. Geoforum, Volume 31, pp. 269-280

Lee, J.E.C., Lemyre, L., 2009. A Social-cognitive Perspective of Terrorism Risk Perception and Individual Response in Canada. Risk Analysis, Volume 29(9), pp. 1265-1280 
Lemyre, L., Turner, M.C., Lee, Jennifer E.C., Krewski, D., 2006. Public Perception of Terrorism Threats and Related Information Sources in Canada: Implications for the Management of Terrorism Risks. Journal of Risk Research, Volume 9(7), pp. 755-774

Loewen, L.J., Steel, G.D., Suedfeld, P., 1993. Perceived Safety from Crime in the Urban Environment. Journal of Environmental Psychology, Volume 13, pp. 323-331

Migliorini, L., Rania, N., Cardinali, P., Manetti, M., 2008. Sense of Safety and the Urban Environment: A Study of Preadolescents and Adolescents. Medio Ambiente $y$ Comportamiento Humano, Volume 9(1y2), pp. 69-89

Milman A., Jones, F., Bach, S., 1999. The Impact of Security Devices on Tourists' Perceived Safety: The Central Florida Example. Journal of Hospitality \& Tourism Research, Volume 23(4), pp. 371-386

Nasar, J.L., Fisher, B., 1993. 'Hot Spots' of Fear and Crime: A Multi-method Investigation. Journal of Environmental Psychology, Volume 13, pp. 187-206

Nasar, J.L., Jones, K.M., 1997. Landscape of Fear and Stress. Environment and Behavior, Volume 29(3), pp. 291-323

Newman, O., 1972. Defensible Space: People and Design in the Violent City, London, Architectural Press

Rittichainuwat, B.N., 2011. Tourists' Perceived Risk toward Overt Safety Measures. Journal of Hospitality \& Tourism Research, Volume 37(2), pp. 199-216

Sassen, S., 2010. When the City Itself Becomes a Technology of War. Theory, Culture \& Society, Volume 27(6), pp. 33-50

Savitch, H.V., 2008. Cities in a Time of Terror. M.E. Sharpe, Inc., New York

Schneider, R., Kitchen, T., 2007. Crime Prevention and the Built Environment. Routledge, Oxon Sheppard, B., 2011. Mitigating Terror and Avoidance Behavior through the Risk Perception Matrix to Augment Resilience. Journal of Homeland Security and Emergency Management, Volume 8(1), pp. 1-19

Sjöberg, L., 2005. The Perceived Risk of Terrorism. Risk Management, Volume 7(1), pp. 43-61

Slovic, P., Weber, E.U., 2002. Perception of Risk Posed by Extreme Events. The Conference on Risk Management Strategies in an Uncertain World 2002. Palisades, New York, April 1213

Stevens, G., Taylor, M., Barr, M., Jorm, L., Griffin, M., Ferguson, R., Agho, K., Raphael, B., 2009. Public Perceptions of the Threat of Terrorist Attack in Australia and Anticipated Compliance Behaviours. Australian and New Zealand Journal of Public Health, Volume 33(4), pp. 339-346

Woods, J., Eyck, Toby A.T., Kaplowitz, S.A., Shlapentokh, V., 2008. Terrorism Risk Perceptions and Proximity to Primary Terrorist Targets: How Close is Too Close? Human Ecology Review, Volume 15(1), pp. 63-70 